\title{
LA CONDUCTA ANIMAL Y LO TRANSANIMAL EN EL HOMBRE EN LA BIOLOGÍA FILOSÓFICA DE HANS JONAS
}

\author{
Alejandro Serani Merlo*- Yván Lailhacar Formigo**
}

En este trabajo se expone y comenta esquemáticamente la biofilosofía de Hans Jonas, poniéndola en relación con su visión del ser humano. Para Jonas la vida se distingue de la materia inerte por la libertad ganada desde la aparición del metabolismo. Percepción y emoción generan un hiato o mediatez entre el interés animal y su satisfacción; la conducta animal sería, entonces, el segundo grado de libertad. Con el ser humano surge un nuevo grado de libertad, que implica un salto ontológico caracterizado por el autor como transanimalidad. Lo transanimal remite a un modo propio de apropiarse del mundo, que se distancia de la satisfacción de las necesidades meramente biológicas, que no reviste utilidad para él, y que lo lleva a encontrarse consigo mismo y reflexionar sobre su propia existencia. En este plano Jonas examina tres signos de lo humano: la herramienta, la imagen y la tumba. La antropología de Jonas entronca con su comprensión de la realidad natural como fenómeno vivo y con su fenomenología de la vida animal. Este planteamiento de Jonas nos parece original y fecundo. Sus aportes iluminan la paleontología contemporánea, aportan criterios para juzgar el nivel de desarrollo humano en toda época y aportan una base sólida donde poder anclar una metafísica.

Palabras clave: Hans Jonas, biofilosofía, transanimalidad, seres vivos, antropología.

\section{ANIMAL BEHAVIOR AND THE TRANSANIMAL IN MAN IN THE PHILOSOPHICAL BIOLOGY OF HANS JONAS}

\begin{abstract}
In this work, some biophilosophical views of Hans Jonas are exposed and contrasted with his anthropology. For Jonas, life distinguishes itself from lifeless matter due to freedom conquered by metabolism. Perception and emotion generate a hiatus between animal impulse and its satisfaction. Animal behavior being the second degree of freedom. With human beings a new degree of freedom arises, that implies an ontological 'jump' characterized by our author as transanimality. This term refers to a new mode of re-appropiation of the world, that puts some distance from a merely biological satisfaction of needs, this mode is 'useless' and conducts the subject to find himself and to reflect on his own existence. In this context Jonas examines three specific human signs: tools, images and tombs. Jonas's anthropology emerges from a particular understanding of living beings and from his enlightening approach to animal behavior. We find Jonas's approach original and intellectually fruitful. His proposal illuminates modern paleontology, provides criteria in order to judge the degree of development of a given human culture, and gives a solid ground for metaphysical developments.
\end{abstract}

Keywords: Hans Jonas, biophilosophy, transanimality, living beings, anthropology.

\footnotetext{
*Pontificia Universidad Católica de Chile, Santiago, Chile. Correo electrónico: aserani@uc.cl

**Servicio de Psiquiatría, Hospital del Salvador, Santiago, Chile. Correo electrónico: ylailhacar2002@yahoo.es
} 
La Antropología de Hans Jonas, fuertemente asentada en su comprensión de la realidad natural y del ser vivo, tiene como base de comparación más próxima la conducta animal. Desde luego la idea que se hace nuestro autor de la vida animal no es la de autómatas al modo cartesiano, ni tampoco la que pudiese proyectar un análisis de sistemas vivos desde la cibernética o la teoría de sistemas. La vida animal, bien que asentada sobre la vida meramente metabólica o biológica, se distingue de ella. Si la vida vegetativa constituye ya un triunfo sobre la materia, y la forma viviente -aun meramente metabólica- es ya "forma emancipada", la vida animal constituye un segundo momento de incremento de libertad, una nueva forma de mediatez. Desde luego, se trata de una emancipación relativa, ya que esta libertad se logra al precio de una dependencia existencial respecto de la materia. Ganancia de libertad operativa, pero pérdida de libertad existencial, existencia frágil, precaria, aniquilable, "ajena al estable ser de la materia carente de vida"1.

Citemos ampliamente un párrafo que Jonas agrega en la edición alemana al comienzo del Ensayo 6 (IV en la edición en inglés) Movimiento y sentimiento: acerca del alma de los animales. En él se subrayan los caracteres generales de la vida, sobre las cuales surgirá la vida animal:

Una vez más: la clausura de la totalidad funcional hacia adentro es,...apertura correlativa al mundo. El sí mismo de la vida particular se opone a todo lo demás como a un mundo exterior...pero esa oposición se actualiza en virtud de la "trascendencia"... como el estar fuera de sí mismo de lo interior en lo exterior. La particularización de la unidad de vida como individuo y su radical apartamiento del universo de lo coordinado e intercambiable entre sí, implican precisamente la capacidad de entrar en contacto con la multiplicidad de lo otro...cuanto más decidida sea la individualidad...más...irá creciendo en longitud y en pluralidad el radio de sus contactos posibles...cuanto más centralizado y puntual sea el yo de la vida, más amplia será su periferia, y viceversa, cuanto más inserto esté todavía en el conjunto de la naturaleza, más indeterminado en su diferencia y más difuminado en su centralidad, más estrecha será su periferia de contactos con el mundo. La vida guarda por principio las distancias respecto del mundo, de cuya homogeneidad se separa la forma retirándose a su propio modo de

1 Jonas, H., El principio vida: hacia una biología filosófica, Trotta, Madrid, 2000, p.150. Jonas, H., The phenomenon of life: toward a philosophical biology, The University of Chicago Press, Chicago \& London, 1966. 
ser, pero precisamente esta distancia proporciona la dimensión para la referencia al mundo que tiene sus raíces en las necesarias relaciones reales...pero va más allá de ellas, llegando hasta la universalidad ${ }^{2}$.

Si es cierto que ya la vida metabólica constituye una "trascendencia" por sobre el fluir de la materialidad, su alcance físico es, sin embargo, limitado, y permanece confinado a la contigüidad y al contacto. La vida vegetativa es actividad $a d$ intra, pero inmovilidad $a d$ extra, implantación en un lugar.

Siguiendo una arraigada tradición aristotélica Jonas afirma taxativamente, "tres características distinguen la vida animal de la de las plantas: motilidad, percepción y emoción"3; tres manifestaciones o facultades "que son expresión de un principio común" 4 . La simultánea aparición de estas características, piensa Jonas, "abre un importante capítulo de la historia de la libertad, que arrancó con la existencia orgánica...y se manifestó por primera vez en la inicialísima intranquilidad de la sustancia metabolizante" ${ }^{\text {. El desarrollo }}$ progresivo de estas capacidades determinaría "una creciente exploración del mundo" y "una creciente individualización del sí mismo", efectos ambos que estarían ligados entre sí, ya que la creciente exploración del mundo acarrearía una mayor complejidad y, como dice nuestro autor: "lo más complejo es también lo más fuertemente individuado". Jonas justifica el emerger de estas nuevas capacidades del mundo animal como desarrollos del elemento de trascendencia propio de la vida, que desde sus etapas orgánicas abre dos horizontes en los cuales la vida penetra y se supera a sí misma incesantemente ${ }^{8}$. Estos serían: internamente, el tiempo, como "la siguiente fase de su existencia hacia la que se va moviendo", y externamente, el "espacio como el lugar del "otro" co-presente del que depende para darse continuación a sí misma".

Recapitulando, y utilizando los términos del autor, podríamos decir que la inicialísima intranquilidad de la sustancia metabolizante en el desarrollo del elemento de trascendencia propio a la vida, que se supera a sí misma incesantemente, genera un doble horizonte: interno uno, -temporal-, abierto al instante sucesivo de la existencia; externo el otro, espacial, abierto al comercio con los demás. Es en la prolongación de este dinamismo que debe comprenderse el surgimiento de la vida animal, surgimiento que supone una discontinuidad dada por la aparición de la percepción, la emoción y el movimiento orientado.

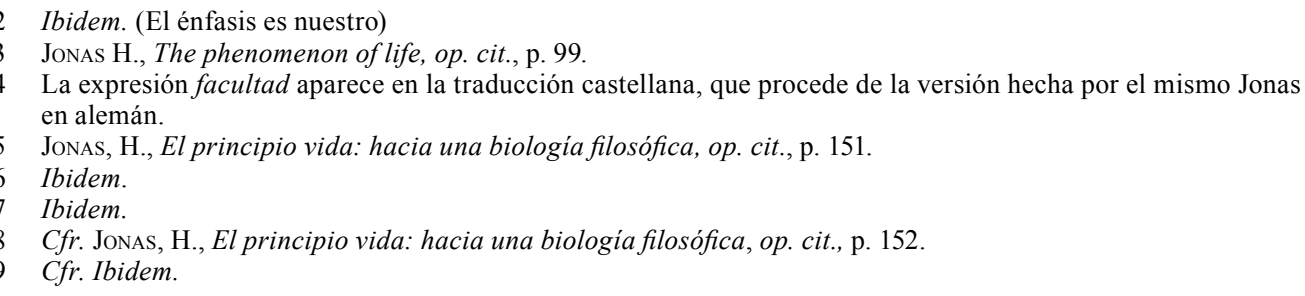


Ahora bien, la percepción a distancia determinará una ampliación de las posibilidades de relación con otros seres en el espacio, y la emoción, por su parte, con objetivos visualizados como alcanzables, que se desean pero que no se poseen. "El movimiento local del animal...se dirige hacia un objeto o se aparta de él; es decir, es persecución o huida"10, "la percepción presenta al objeto como "no aquí, pero sí allí”; el deseo presenta al objetivo como "todavía no pero esperable": la facultad de moverse, guiada por la percepción e impulsada por el deseo, transforma el allí en aquí y el todavía no en ahora"l1. "El gran secreto de la vida animal -concluye Jonas- reside precisamente en el hiato que es capaz de mantener abierto entre interés inmediato y satisfacción mediada, es decir, en la perdida de inmediatez que corresponde a la ganancia en campo de posibilidades"12.

Un nuevo tipo de contraste se revela a partir de lo anterior entre la vida meramente biológica y la vida animal. La relación dentro-fuera instaurada desde el momento mismo del surgimiento del organismo como existente individual, se expresa para la planta en términos de organismo/medio, mientras que para el organismo animal su medio es un "entorno". "La planta - dice nuestro autor- está eximida de la necesidad de moverse (a la par que privada de la posibilidad de hacerlo)...para las plantas "entorno" significa algo fundamentalmente distinto que para los animales"13. En el animal "los objetos de su entorno relevantes para él siempre se encuentran a cierta distancia"14, existe un hiato temporal entre la necesidad y la satisfacción y se distingue la acción del fin. La acción vital que satisface las necesidades del animal, a diferencia de lo que ocurre en la planta, está mediada por un movimiento exterior, este rodeo es la sede de la libertad y del riesgo, anejos a este tipo de vida ${ }^{15}$.

La mediatez propia de la existencia animal está en la raíz de la motilidad, de la percepción $y$ del sentimiento. Crea al individuo particular que se enfrenta al mundo. Este mundo es acogedor a la par que amenazante...este modo de ser precario y expuesto obliga a permanecer en vigilia y a esforzarse. Respondiendo al atractivo de la presa, del que la percepción ha dado noticia, la vigilia se transforma en la tensión de la caza y en el disfrute de la satisfacción, pero también conoce el tormento del hambre, el látigo del temor, el medroso esfuerzo de la huida. También la persecución puede terminar en el desengaño del fracaso. Dicho brevemente: lo indirecto de la existencia animal se reserva en el estado de vigilia que le es propio las posibilidades gemelas del placer y del sufrimiento, maridadas las dos con el esfuerzo. La capacidad de experimentar uno y otro crece como una y la misma a lo largo de la evolución, y estar expuesto al sufrimiento no es una carencia que prive de algo a la capacidad de gozar, sino su necesario complemento ${ }^{16}$.

10 JonAs, H., El principio vida: hacia una biología filosófica, op. cit., p. 153.

11 Idem., p. 154.

12 Ibidem.

13 Jonas, H., El principio vida: hacia una biología filosófica, op. cit., p. 156.

14 Ibidem.

15 JonAs, H., El principio vida: hacia una biología filosófica, op. cit., p. 157.

16 Idem, op. cit., p. 158. 
En su reflexión sobre la vida animal, nuestro autor nos invita a dar un último: ¿cuál es la superioridad, la ganancia o la ventaja por la cual el animal asume una vida precaria y pasajera, "una aventura de mortalidad"? La percepción y la emoción no se deben juzgar solamente como "medios de supervivencia" sino también como:

...cualidades de la vida misma que se trata de conservar, y por lo tanto como aspectos del fin de la conservación... El animal dotado de la capacidad de sentir tiende a conservarse como ser sentiente, no como ser meramente metabolizante...sin estas facultades habría mucho menos que conservar, pero al haber menos que conservar habría también, en esa misma proporción, menos medios con los que conservarlo. Al cabo, es el hecho de la individuación el que decide el litigio entre el animal y la planta. La constitución original del organismo, ya incluso en el nivel del organismo monocelular, manifiesta individualidad como una osadía de la libertad con la que una forma mantiene su identidad a través de las modificaciones de su materia. La libertad es compensada dialécticamente por la necesidad, la independencia por la dependencia. La mismidad aqui preformada como entre sombras tiene desde el principio su opuesto en la aliedad del mundo. La ulterior acentuación de este dualismo, con toda la carga a él inherente, no es otra cosa que la acentuación de la vida misma. La dialéctica de la vida tiene que comunicar necesariamente un doble filo a todo estado de la misma que haya alcanzado un cierto desarrollo ${ }^{17}$.

Sus goces tienen como lado negativo el sufrimiento, su soledad encuentra compensación en la posibilidad de comunicarse: la ganancia no está en uno de los lados del balance, sino en la coexistencia de los dos, es decir, en el crecimiento de la mismidad con la que el "organismo" desafió originariamente a la indiferente naturaleza...en su creciente amplitud la libertad de la vida encontró espacio para todos aquellos modos de relación - perceptiva, activa y sentiente- que justifican la separación por el procedimiento de agrandarla al máximo y, si bien dando rodeos, acaban recuperando la unidad perdida ${ }^{18}$.

Hagamos una breve síntesis y comentario a lo que hemos expuesto resumidamente antes de ingresar en el tratamientos de algunos temas propiamente antropológicos de la obra de Jonas.

Se ha dicho - a nuestro juicio erróneamente- que la filosofía de Aristóteles es una proyección o extensión de su idea de los seres vivos al ámbito cosmológico y aún metafísico. Lo que no parece verdadero de Aristóteles podría, en cambio, serlo con respecto a la filosofía de Hans Jonas. De hecho, no sería difícil encontrar entre sus escritos afirmaciones, sino idénticas, al menos concordantes con lo que se acaba de proponer. Es él mismo quién

17 Idem., pp. 158-159.

18 Idem., p. 160. 
ha afirmado que su obra de mayor contenido y valor filosófico es The phenomenon of life: toward a philosophical biology y no The imperative of responsibility, que ha sido mucho más leída y difundida que la anterior. Es él mismo también quién ha defendido la íntima e indisoluble conexión existente entre sus planteamientos biofilosóficos y sus proposiciones bioéticas y filosófico-políticas. Esto último en contra de lo afirmado por algunos de sus más fervientes seguidores y admiradores, sobre todo en Alemania.

Remitir entonces a la biofilosofía del metabolismo y a su comprensión del organismo animal, no es una mera introducción retórica a la antropología de Jonas, es mostrar su base de apoyo fundamental. Sin entrar todavía en un examen crítico de lo que hemos intentado exponer, rescatemos por el momento algunos conceptos fundamentales que reaparecerán en su antropología.

En primer lugar, la originalidad de lo vivo. Llamémosle por razones más sociológicas que filosóficas: fenómeno de la vida o principio vida, más allá de las palabras es claro que en Jonas estamos frente a una afirmación de significación ontológica. Se trata aquí de un modo original de existencia y de existentes, se trata -aunque la expresión no abunde en su obra- de living beings y no sólo de sistemas vivos, unidades vivas u organismos.

En segundo lugar, se afirma en estos y otros textos una gradación ascendente que alcanza sin embargo niveles, capas, órdenes o grados superiores, irreductibles a los estratos previos. El primer hito o grado es por supuesto la vida misma, la vida metabólica, la vida meramente biológica o vegetativa. El segundo viene dado por la vida animal, por la aparición brusca y simultánea de las tres capacidades de percepción, locomoción y emoción. Jonas privilegia -sin excluir- la expresión de grados o niveles de mediatez. Grados que son como una suerte de cristalización de un dinamismo auto-trascendente, común a todo lo vivo.

En tercer lugar el reconocimiento de lo vivo como realizando un especial maridaje entre una realidad de orden formal y una materia que fluye sin desaparecer como tal en su entidad. Materia que podríamos decir es "convocada" por la forma a la realización de una unidad viviente singular. Pero: ¿qué es esta forma y qué esta materia, y cómo realizan entre ambas la unidad? Paradojalmente vemos en este tema uno de los puntos más lúcidos y a la vez más nebulosos del pensamiento cosmológico de Jonas. En efecto, conocemos su distanciamiento tajante del dualismo, al menos del cartesiano, pero, por otro lado, no deja de sorprender la precaria justificación para la integración materio-formal que constituye al viviente.

Finalmente, debe subrayarse la noción de límite, horizonte que la vida supone y a la vez crea, y que implica la aparición de un medio, entorno o mundo, según sea el caso, de los seres vivos o para los vivos. En el caso particular de los animales este entorno tiene dos dimensiones, una temporal y la otra espacial, que Jonas relaciona con la emoción y la percepción respectivamente. 


\section{III}

Con la aparición del hombre asistiríamos al surgimiento de un nuevo umbral de mediatez, cuyo paso constituye al parecer un nuevo grado ontológico. Para comprender mejor la naturaleza de este umbral, que nuestro autor denomina de transanimalidad, Jonas propone examinar tres signos o manifestaciones características de lo humano con el fin de discernir su sentido: la herramienta, la imagen y la tumba.

La herramienta -según él- "es un objeto inerte artificialmente preparado, que se interpone (interpola) como mediación entre el órgano corporal ejecutor (la mayoría de las veces la mano) y el objeto extracorporal sobre el cual se ejerce"19. Objeto utilizado para modelar, pero que él, a su vez, es modelado. La fabricación de la herramienta puede a su vez exigir otras herramientas, lo que constituye una mediación de segundo grado. Esta espiral de mediaciones sucesivas una vez desencadenada va multiplicándose y se encontraría en la base de la explosión tecnológica moderna.

La herramienta, recalca el filósofo alemán, "no deriva de ninguna función orgánica y no está sometida a ninguna programación biológica" ${ }^{20}$. Esta es justamente la diferencia entre la herramienta humana y la telaraña, el nido o el hormiguero, que no son, ni útiles ni obras de arte. La inorganicidad del medio artificial sería, entonces, el reverso de la libertad que comanda su invención. Libertad que comporta un elemento eidético. Presentada primero a la imaginación, esta forma es percibida intuitivamente en el modelo logrado, y es a causa de esta percepción intuitiva de la forma que ella puede ser reproducida infinidad de veces sobre materiales diversos y en circunstancias diversas. Todo esto supone -dice Jonas- "fuerza eidética de la imaginación y control eidético de la mano"21: "La libertad en la creación de la herramienta -subraya finalmente nuestro autor- que es transanimal por su motivación y su determinación, está todavía - debido a su carácter utilitario- en la más estrecha relación con el dominio de la necesidad animal, a cuyas necesidades ella sirve en un modo transanimal: es en razón de esto que es posible concebir fácilmente la existencia de transiciones fluidas entre logros animales y logros humanos".

La fabricación de imágenes, por el contrario, "manifiesta no una diferencia de grado, sino la total diferencia de esencia con el animal". Ya lo hace sentir, la inutilidad biológica de toda representación pura, pero en la imaginería -sostiene Jonas- "uno se apropia el objeto de una manera nueva, no práctica, y el hecho que el interés por él pueda centrarse en su eidos testimonia precisamente de una nueva relación objetal", "es el eidos en tanto que tal que deviene objeto de experiencia".

19 Jonas, H., Pensar sobre Dios y otros ensayos, Herder, Barcelona, 1998, p. 43.

20 Ibidem.

21 Jonas, H., Pensar sobre Dios y otros ensayos, op. cit., p. 49. 
El análisis fenomenológico de los diferentes procesos mentales supuestos por la elaboración de imágenes revela lo que nuestro autor llama "una transanimalidad específicamente humana". "Un control eidético de la motricidad, es decir una actividad muscular no regida por esquemas fijos de excitación y reacción, sino por una forma libremente escogida, interiormente imaginada e intencionalmente proyectada. El control eidético de la motricidad, con su libertad en la realización exterior, completa el control eidético de la imaginación, con su libertad de concepción interior. El homo pictor-continúa Jonas-que expresa estas dos libertades en una evidencia indivisible, marca el punto en el que el homo faber y el homo sapiens se encuentran ligados -mejor aún- el punto en el que se revelan como siendo un mismo y único ser"22.

Finalmente, nuestro autor dirige su examen al fenómeno de la sepultación ritual; la sepultura o la tumba comprendida como "la memoria de los difuntos perpetuada en el culto funerario y en otras formas visibles" ${ }^{23}$. Actividad que es todavía más biológicamente inútil que la fabricación de imágenes, y ligada a representaciones de creencias que desafían la apariencia de nuestra finitud, yendo más allá de todo lo visible hacia el invisible, y del sensible al supra-sensible. Pensando en el más allá y en el después, el ser humano medita sobre el aquí y el ahora de su existencia; él medita en definitiva sobre sí mismo. "Consciente de su mortalidad, él no puede vivir en tanto que ser humano sin una comprensión de sí mismo...así de las tumbas surge la metafísica... pero también la historia en tanto que memoria del pasado" 24 .

En el vacio del abismo abierto en esta confrontación consigo mismo encuentran lugar las más altas exaltaciones y las más profundas depresiones de la experiencia humana. En efecto, el hombre también está abierto a la desesperanza; él sólo puede cometer el acto de suicidio $^{25}$. La sepultura nos dice que aqui un ser, sometido a la mortalidad, reflexiona a la vida y a la muerte, desafía el testimonio de sus ojos y eleva el pensamiento al invisibleponiendo la herramienta y la imagen a su servicio ${ }^{26}$. Física, arte y metafísica, apuntadas desde la noche de los tiempos, por el útil, la imagen y la tumba, son...dimensiones originales en la relación del hombre al mundo.

De este análisis centrado en detectar lo específicamente humano en los albores de la cultura, nuestro filósofo extrae conclusiones de orden general que le permiten emitir un penetrante y sorprendente juicio crítico acerca de la actualidad:

Las herramientas por razones bien comprensibles, nunca faltarán. Pero la imagen y la tumba, una y otra representando un lujo superior del hombre atormentado por la necesidad que la naturaleza le impone, pueden faltar aquí o allá, por diversas razones.

22 Ibidem

23 Jonas, H., Pensar sobre Dios y otros ensayos, op. cit., p. 51.

24 Ibidem.

25 Jonas, H., Pensar sobre Dios y otros ensayos, op. cit., p. 53.

26 Ibidem. 
Pese a ello, no dejamos de contar la capacidad de producirlas entre las características que constituyen la existencia humana, y en ninguna cultura están del todo ausentes. La nuestra pone en la actualidad el mayor énfasis en lo que se anuncia en la herramienta: la técnica y la ciencia natural que está a su servicio. Lo que se hallaba más próximo a la finalidad biológica y su dinámica de selección, lo que apareció primero como tributo a la dependencia de la naturaleza y que se oponía a ésta como ayuda, esto es lo que actualmente sobresale con sus nunca sospechados éxitos que se van superando siempre de nuevo y que dominan toda nuestra existencia, destacando entre todo lo demás que nos distingue "de todos los seres que conocemos". No olvidemos por eso que también los otros horizontes transanimales, extraños al progreso-también la metafísica, actualmente desprestigiada-forman parte del todo de la especie humana ${ }^{27}$.

Nuestra época en consecuencia llevaría la marca y el lastre de un utilitarismo, ciertamente sofisticado, pero utilitarismo al fin, a la espera de épocas con aspiraciones más nobles de índole artístico o metafísico.

\section{IV}

Habiendo expuesto de manera esquemática y sucinta el tratamiento que hace Jonas de la vida animal y de lo transanimal en el hombre, corresponde ahora hacer un catastro, una valoración y un comentario crítico de lo expuesto. No pretendemos con lo dicho haber llevado a cabo una exposición completa de la biofilosofía y de la antropología de Jonas. Esa tarea requeriría un examen exhaustivo de su obra, y un estudio de vasto alcance que nos parece todavía está por realizarse. Lo que hemos hecho ha consistido aproximadamente en seguir de cerca un argumento que Jonas desarrolla en la madurez de su vida y de modo circunstanciado en su obra The phenomenon of life de 1966, y que resume y complementa a grandes trazos a los ochenta y nueve años en su última obra publicada en alemán: Philosophische Untersuchungen und metaphysische Vermutungen (Indagaciones filosóficas y conjeturas metafísicas) de 1992, un año antes de su muerte, libro que en castellano lleva por título Pensar sobre Dios y otros ensayos. Se trata, podríamos decir, de una vasta panorámica bio-cosmológica en la que intenta señalar los grandes hitos o categorías en las que se enmarca la diversidad de lo viviente. A partir de lo anterior intentaremos algunas tesis interpretativas.

El reconocimiento de la originalidad de lo vivo es ciertamente el eje articulador de la biofilosofía jonasiana. Esta postura intelectual se mantiene y profundiza en su reconocimiento de la originalidad del comportamiento animal y en el de la especificidad de lo humano por contraste con lo meramente animal. 
La forma vital que no es la resultante de las acciones físico-químicas que se realizan en el organismo vivo, sino su causa, apunta a restablecer el orden de las evidencias, trastrocado por el mecanicismo materialista. En efecto, ya desde la vida metabólica se aprecia el surgimiento de una individualidad que va en ascenso a medida que se alcanza el segundo y tercer grado de mediatez.

El evolucionismo, señala Jonas, al afirmar la transición gradual de lo animal a lo humano, contribuyó sin buscarlo a recuperar la originalidad de la vida animal restituyéndole al animal las facultades que el cartesianismo le había sustraído. El análisis fenomenológico de Jonas, sin ser completamente original si se lo compara con la fineza del llevado a cabo por la tradición aristotélica, es, sin embargo, estimulante frente al empobrecimiento de la vida animal llevado a cabo por el mecanicismo cibernético o por el conductismo de Pavlov y Skinner.

El análisis de lo transanimal en el hombre, nos parece, es lo más original y hermenéuticamente fecundo de la biofilosofía jonasiana. Sus desarrollos acerca del uso de herramientas, de la producción de imágenes en el arte rupestre y del enterramiento ritual, iluminan la investigación paleontológica contemporánea y a la vez reciben de ella una confirmación. Y no sólo eso, sino que, como hemos visto, aportan criterios diagnósticos para juzgar el nivel de desarrollo humano de la cultura en toda época. Si bien sus admirables acercamientos fenomenológicos no desembocan en una teoría ni menos en una metafísica del conocimiento explícitamente desarrolladas, sus análisis aportan para ellas una base inestimable. Eso en cuanto al catastro sumario y a la valoración de los planteamientos de Jonas examinados por nosotros.

Finalmente, algunas consideraciones acerca de la actualidad y de la validez de algunas de las categorías epistemológicas y metafísicas que subyacen al pensamiento jonasiano.

La lectura de Jonas nos sitúa frente a un tratamiento de los temas hoy en día a todas luces inusual. Intentar en nuestra época una biología filosófica que, sin confundirse con las ciencias naturales de lo viviente, pueda instalarse frente a ellas en un plano no sólo de igualdad, sino que incluso de superioridad, constituye un hecho digno de celebrarse. El discurso culturalmente hegemónico de las ciencias naturales y de la técnica a ellas asociada, no sólo parece tener acallada hoy en día la posibilidad de un discurso filosófico acerca de las realidades naturales, sino que más aún, suele considerar esta posibilidad como cognoscitivamente superflua y epistemológicamente ilegítima.

Haciendo caso omiso de la incorrección política de una tal tentativa, Jonas emprende esta tarea con convicción y con sentido de urgencia. Tras esto no hay sólo un mero interés 
especulativo, y ni siquiera el intento de colmar un vacío cultural, se trata de un imperativo ético de mayor cuantía. La sustitución operada por la ciencia natural en el plano ideológico cultural, que Jonas llega a calificar de impostura, ha llegado a tener, a través de su longamanus secular, la técnica moderna, consecuencias sobre la vida cotidiana de los pueblos, de dimensiones nunca antes experimentadas por la humanidad. Su libro Imperativo de la Responsabilidad: una ética para la edad tecnológica es, en este sentido, una suerte de clamor de advertencia y de lamento profético. Los largos años pasados en el campo de batalla han terminado por hacer mella en el corazón y en el intelecto de este intelectual judío-germano. La guerra le ha enseñado con realismo y crudeza que los errores filosóficos no son inocuos, y que los devaneos ideológicos terminan pagándose con sangre de inocentes. El recuerdo de la masacre de su propia familia y de sus amigos en los campos de concentración, está ahí para recordárselo.

Así y todo Jonas no es un intelectual de batalla, un filósofo engagé. Él es un filósofo, un sabio, en el más genuino y tradicional de los sentidos. Su tarea no es denunciar o condenar, su misión es iluminar. Y esa tarea la llevará a cabo aunque sea al precio de navegar a contracorriente. No le será fácil ser comprendido al intentar develar los errores del mecanicismo materialista, del evolucionismo darwinista, del materialismo cibernético, del encarnizamiento tecnológico y terapéutico en el ámbito biomédico. La prédica filosófica de Jonas no es apta para atraer multitudes, menos en aquella Norteamérica que oficia de epicentro creador y difusor de la ciencia y de la técnica modernas.

No obstante lo anterior, Jonas será un filósofo respetado y escuchado, -si bien poco comprendido y menos seguido-. Se lo valora y se lo respeta porque discute los problemas con conocimiento, serenidad, apertura y altura. Vale también para él, lo que expresó a propósito de Hannah Arendt, en su discurso fúnebre, refiriéndose al impacto filosófico de su amiga en los EE.UU. de Norteamérica. Tal vez no haya resuelto muchos problemas, decía Jonas, pero ha determinado que después de ella, estos mismos problemas se piensen ahora en un nivel superior ${ }^{28}$.

El pensamiento biofilosófico de Jonas no sólo ha sido y es políticamente incorrecto en el ámbito cultural contemporáneo. Es también difícil. Es difícil porque es culto, informado, inteligente, pero también porque, suele ser más sugerente que explícito, y también porque -como advierte Clarence Finlayson- en materias profundas, no siempre es posible ser muy transparente.

Pensamos que su posición de fondo es realista, por más que se encuentre mentalmente interceptada. La formación fenomenológica de Jonas se nota, lo ayuda, y también a veces le pesa, como también le pesa la tradición idealista germana. Y, aunque parezca inverosímil, también un cierto cartesianismo.

Cfr. Jonas, H., Entre le Néant et l'Éternité, Belin, France, 1996, p. 80. 
Comencemos por lo último. La ficción acerca de los extraterrestres que llegan a nuestro planeta, y que califica un tanto pomposamente de "estrategia rigurosa", desarrollada al inicio de su ensayo 'Homo pictor': la producción de imágenes y la libertad del hombre, estrategia que pretende le permitiría a estos extraterrestres detectar una imagen como hecha inequívocamente por un ser humano, tiene mucho de cartesiano. Más que captar lo esencial pareciera que lo que aquí interesa es no equivocarse. De hecho, por eso prefiere, por su simplicidad, tomar como tema de discusión la imagen y no el lenguaje, por más que reconozca más tarde que la producción de imágenes supone ya adquiridas las estructuras fundamentales del lenguaje. La misma estrategia de experimento ficticio que desarrolla no llega a convencer, por la cantidad de presupuestos que ella acarrea, como suele ocurrir con las forzadas experiencias mentales que desarrolla el propio Descartes. Más de alguna vez se aproxima también a Descartes con su idea de la materia como algo homogéneo, inerte, indiferenciado, y hasta difícilmente corruptible ${ }^{29}$. Esta idea pobre que tiene de lo inorgánico dificultará, posteriormente, su concepción unitaria del ser vivo como una forma que convoca a una materia, que integrándose bajo la forma del ser vivo no pierde sin embargo su sustancialidad. Al punto que podemos preguntarnos si logra verdaderamente darle sustento racional a ese su monismo integral, que defiende con tanta lucidez y convicción. Debe reconocerse no obstante que en sus especulaciones cosmogónicas de la edad tardía reconoce en la materia una virtualidad de actualización vital y espiritual que en sus escritos anteriores no se había manifestado.

Su pobre y ambivalente consideración de la materia inorgánica hace que su alusión a la forma aristotélica termine siendo más retórica que eficaz. Comprende, en efecto, incompletamente el planteamiento de Aristóteles, o lo comprende mal. De hecho no recoge la dualidad potencia/acto que es lo único que podría haber dado unidad a su monismo integral. La fenomenología que él hace de la relación materia/forma es magistral; pero fenomenologizar no es explicar, por muy bien que se fenomenologice.

La insistencia en el carácter de tendencia a auto-trascenderse de lo vivo, y el carácter ascendente y gradual del proceso evolutivo lo aproxima por momentos al evolucionismo de Spencer, y aunque mantiene claramente las distancias del evolucionismo materialista de Darwin, tanto Darwin como Jonas terminan cada uno a su modo rindiendo su tributo al evolucionismo spenceriano.

El criticismo kantiano está frecuentemente como telón de fondo inhibiendo el despliegue de su talante y de sus convicciones realistas. Cuando se trata de pensar sobre Dios, dirá con una cierta solemnidad en el prefacio de su último libro firmado en noviembre de 1991 lo siguiente: "respeto el ascetismo de quedarse parado en los límites, que la filosofía aprendió desde Kant" a renglón seguido, sin embargo, parece querer desprenderse del incómodo yugo que le impone esta ascética, de mantenerse dentro de los límites de toda

29 Cfr. Jonas, H., Pensar sobre Dios y otros ensayos, op. cit., pp. 26-27. 
experiencia posible. Afirma nuestro autor: "Pero sigue siendo inextinguible el derecho de aquellos espíritus que se sienten empujados a llevar su preguntar incluso allí donde éste ya sólo puede esperar respuestas adivinatorias y expresables en circunscripciones figuradas. Sin la pretensión de ser conocimiento, este meditar también quiere ser transmitido y según me dice la experiencia, encontrará algunas resonancias". ¿Qué podrá querer transmitir un filósofo, como un derecho inextinguible, aún en circunscripciones figuradas, si no es un conocimiento? ¿Por qué un pensador en el umbral de la muerte tiene que pedir permiso para expresar sus pensamientos más profundos, calificándolos de "conjeturas metafísicas" o de "expresiones adivinatorias" que no pretenden ser conocimiento?

Que Jonas en su fuero interior está dispuesto a sacudirse el yugo kantiano está más que patente en su doctrina sobre la vida. La vida para Jonas no puede ser aprehendida desde su exterioridad, que es a donde alcanza la percepción en el ámbito de las experiencias posibles. Es porque tenemos un cuerpo y somos cuerpo que podemos, como desde un observatorio privilegiado hablar de la vida, de nuestra vida, y de la vida en general. La vida supone, dirá Jonas, interioridad, interioridad en lucha, interioridad e individualidad creciente y ascendente. Reconoce que su planteamiento tiene algo de antropomórfico, pero defiende un antropomorfismo legítimo, por lo demás insoslayable. Insoslayable porque no se trata en realidad de un antropomorfismo, que siempre es ilegítimo, sino una aceptación del constitutivo antropocentrismo del conocer filosófico humano. Todo trascendentalismo filosófico se hará siempre desde el conocimiento humano y esto no es una imperfección, sino su limitación constitutiva.

Por ello también nos parece que la afirmación de la subjetividad del ser vivo, que supera sin duda las limitaciones cognoscitivas del kantismo, lejos de constituir una incoherencia metodológica, es la respuesta consciente y madura de un realismo metafísico que en Jonas se encuentra más incoado que realizado.*

\section{Bibliografía}

Jonas, Hans, El principio vida: hacia una biología filosófica, Trotta, Madrid, 2000.

Entre le Néant et l'Éternité, Belin, France, 1996.

, Pensar sobre Dios y otros ensayos, Herder, Barcelona, 1998.

, The phenomenon of life: toward a philosophical biology, The University of Chicago Press, Chicago \& London, 1966.

* Artículo recibido: 25 de noviembre de 2014. Aceptado: 15 de diciembre de 2014. 